\title{
Inspiratory fraction and exercise impairment in COPD patients GOLD stages II-III
}

\author{
A.L.P. Albuquerque, L.E. Nery, D.S. Villaça, T.Y.S. Machado, C.C. Oliveira, \\ Â.T. Paes and J.A. Neder
}

ABSTRACT: The inspiratory-to-total lung capacity ratio or "inspiratory fraction" (inspiratory capacity(IC)/total lung capacity (TLC)) may be functionally more representative than traditional indices of resting airflow limitation and lung hyperinflation in patients with chronic obstructive pulmonary disease (COPD).

In the present retrospective study, a comparison was made of the individual performance of post-bronchodilator IC, IC/TLC and forced expiratory volume in one second (FEV 1 ) in predicting a severely reduced peak oxygen uptake $\left(\mathrm{V}^{\prime} \mathrm{O}_{2} ;<60 \%\right.$ predicted) in $44 \mathrm{COPD}$ patients Global Initiative for Chronic Obstructive Lung Disease stages II-III (post-bronchodilator FEV1 ranging from $31-79 \%$ pred).

Patients with lower IC/TLC values $(\leqslant 0.28)$ showed increased lung volumes and reduced exercise capacity as compared with other subjects. Following a multiple linear regression analysis, only IC/TLC and FEV 1 remained as independent predictors of $V^{\prime} O_{2}\left(r^{2}=0.33\right)$. A receiver operating characteristic (ROC) curve analysis revealed that an IC/TLC $\leqslant 0.28$ had the highest specificity $(89.6 \%)$, positive predictive value $(80 \%)$ and overall accuracy $(86.3 \%)$ in identifying patients with $\mathrm{V}^{\prime} \mathrm{O}_{2}<60 \%$ pred. In addition, the area under the ROC curve tended to be higher for IC/TLC than IC.

In conclusion, post-bronchodilator total lung capacity-corrected inspiratory fraction provides useful information in addition to forced expiratory volume in one second and inspiratory capacity, to estimate the likelihood of chronic obstructive pulmonary disease patients to present with severely reduced maximal exercise capacity.

KEYWORDS: Chronic obstructive pulmonary disease, dyspnoea, exercise, inspiratory fraction, lung hyperinflation, lung volumes

xercise intolerance is the hallmark of chronic obstructive pulmonary disease (COPD), being ascribed to complex interactions between ventilatory, cardiovascular and peripheral muscle abnormalities [1]. Amongst the pulmonary-ventilatory mechanisms that could contribute to exercise impairment in these patients, dynamic hyperinflation (DH) seems to be of special relevance [1, 2]. In this context, inspiratory capacity (IC) at rest and during exercise have been shown to be superior to traditional measures of airflow obstruction (such as forced expiratory volume in one second (FEV1)) in predicting exercise impairment and improvement in tolerance to effort after bronchodilators, especially in patients with more advanced disease [3-5]. However, IC measurements in isolation may provide insufficient information about the actual elastic load during exercise and, therefore, patients' ability to sustain exercise. CASANOVA et al. [6] have argued that IC correction for the total lung capacity (TLC) would provide a better characterisation of the volume fraction available for inspiration than IC alone. In fact, this so-called "inspiratory fraction" (IC/ TLC) has been found to constitute an important prognostic factor in moderate-to-severe COPD. Another prospective study [7] showed that air trapping, expressed as increased residual volume (RV)/TLC ratio, was a powerful predictor of mortality in patients with COPD. To the current authors' knowledge, however, no previous study has systematically evaluated the value of resting IC/TLC in predicting maximal exercise tolerance in this patient population.

Therefore, the primary objective of this study was to investigate whether the inspiratory fraction would be useful in predicting maximal exercise capacity in COPD patients presenting with increased static lung volumes at rest.

\section{AFFILIATIONS}

Pulmonary Function and Clinical Exercise Physiology Unit, Dept of Medicine, Division of Respiratory Diseases, Federal University of Sao Paulo (UNIFESP), São Paulo, Brazil.

\section{CORRESPONDENCE}

J.A. Neder

Pulmonary Function and Clinical Exercise Physiology Unit (SEFICE)

Respiratory Division

Dept of Medicine

Federal University of Sao Paulo

Paulista School of Medicine

(UNIFESP-EPM)

Rua Professor Francisco de Castro 54

Vila Clementino, CEP04020-050

Sao Paulo

Brazil.

Fax: 551155752843

E-mail: albneder@pneumo.epm.br

Received:

March 212006

Accepted after revision:

June 292006

SUPPORT STATEMENT

This work is supported by a research grant from FAPESP (Fundação de

Amparo à Pesquisa do Estado de São Paulo, São Paulo, Brazil) No. 04/ 15891-9. A.L.P. Albuquerque is a

recipient of a scholarship grant from CAPES (Coordenadoria de Aperfeiçoamento do Pessoal de Nível Superior, Brazil). J.A. Neder is an established investigator (level II) of the Conselho Nacional de Desenvolvimento Científico e Tecnológico (CNPq), Brazil. 


\section{METHODS}

\section{Subjects}

The study population comprised 44 patients ( 33 males and 11 females) who had participated in an unpublished investigation on the effects of neuromuscular electrical stimulation on peripheral muscle function and structure. All subjects had a clinical and functional diagnosis of COPD according to the Global Initiative for Chronic Obstructive Lung Disease (GOLD) criteria (stage $\mathrm{II}=24$ and stage $\mathrm{III}=20$ ) [8], presenting with FEV1/forced vital capacity (FVC) ratio $<0.7$ and FEV1 $<80$ but $>30 \%$ predicted. In addition, all patients were required to present with increased static lung volumes at rest. Patients were clinically stable for $\geqslant 4$ weeks and were optimised in terms of medical therapy, including short- and long-acting $\beta_{2^{-}}$ adrenergics, short- and long-acting anticholinergics and inhaled steroids. Exclusion criteria were as follows: suspected asthma; other systemic conditions that could contribute to dyspnoea or exercise limitation, such as heart failure or metabolic disorders; and resting arterial oxygen saturation measured by pulse oximetry $\left(\mathrm{Sp}, \mathrm{O}_{2} ;<90 \%\right)$. Patients gave informed consent and the study protocol was approved by a Medical Ethics Committee.

\section{Measurements}

\section{Anthropometry}

Height was obtained to the nearest $0.5 \mathrm{~cm}$ with subjects standing barefoot; body mass was measured with subjects in light clothing and was established to the nearest $0.1 \mathrm{~kg}$. Body mass index (BMI; $\mathrm{kg} \cdot \mathrm{m}^{-2}$ ) was then calculated.

\section{Pulmonary function}

Spirometric tests were performed by using the CPF System ${ }^{\mathrm{TM}}$ (Medical Graphics Corp., St Paul, MN, USA), with airflow measured by a calibrated Pitot tube (PreVent Pneumotach ${ }^{\mathrm{TM}}$; Medical Graphics Corp.). The subjects completed at least three acceptable maximal forced and slow expiratory manoeuvres: in order to assess exercise capacity under improved ventilatory conditions, the patients were tested $20 \mathrm{~min}$ after the inhalation of $400 \mu \mathrm{g}$ of salbutamol via a metered-dose inhaler. FVC, FEV1 and IC were recorded in body temperature and pressure, saturated conditions. Predicted values were those for the adult Brazilian population [9].

The diffusing capacity of the lung for carbon monoxide (DL,CO) was measured by the modified Krogh technique (single breath); subjects performed two acceptable and reproducible tests, with the results being within $10 \%$ or $3 \mathrm{~mL} \cdot \mathrm{CO} \cdot \mathrm{min}^{-1}$. $\mathrm{mmHg}^{-1}[10]$. TLC (L) and RV (L) were obtained by constantvolume, different-pressure body plethysmography and expressed as a percentage of the predicted value according to Brazilian standards [11]. Air trapping was defined as increased RV/TLC and RV ( $>0.4$ and $>140 \%$ pred, respectively), TLC values $>120 \%$ pred were assumed to be indicative of lung hyperinflation [12]. Arterial partial pressure for oxygen $\left(\mathrm{Pa}_{2} \mathrm{O}_{2}\right)$ and carbon dioxide $\left(\mathrm{Pa}_{\mathrm{a}} \mathrm{CO}_{2}\right)$ were measured $(\mathrm{mmHg})$ in anaerobic conditions.

\section{Cardiopulmonary exercise test}

Symptom-limited, ramp-incremental cycle ergometer exercise tests were performed on a digital computer-based exercise system ( $\mathrm{CardiO}_{2}$ System; Medical Graphics Corp.) with breath-by-breath analysis of metabolic, ventilatory and cardiovascular variables. The rate of power increment was individually selected (usually $5-10 \mathrm{~W} \cdot \mathrm{min}^{-1}$ ) to provide an exercise duration of $>8$ but $<12 \mathrm{~min}$. The following data were recorded as mean of $15 \mathrm{~s}$ : pulmonary oxygen uptake $\left(V^{\prime} \mathrm{O}_{2} ; \mathrm{mL} \cdot \mathrm{min}^{-1}\right)$; minute ventilation $\left(V^{\prime} \mathrm{E} ; \mathrm{L} \cdot \mathrm{min}^{-1}\right)$; respiratory rate $(\mathrm{RR})$ and tidal volume $(V \mathrm{~T} ; \mathrm{L})$. Peak $V^{\prime} \mathrm{O}_{2}$ was the highest value found at exercise cessation; predicted values were in line with those of NEDER et al. [13] for the adult Brazilian population. In the present study, a peak $V^{\prime} \mathrm{O}_{2}<60 \%$ predicted was considered indicative of a severely-reduced maximum aerobic capacity [13]. Cardiac frequency $(f C, b p m)$ was determined using the $\mathrm{R}-\mathrm{R}$ interval from a 12-lead online electrocardiogram. Subjects were also asked to rate their "shortness of breath" at peak exercise using the 0-10 Borg's category-ratio scale [14]. Dyspnoea ratings were also corrected for the ongoing level of total ventilatory stress (dyspnoea/ $V^{\prime} \mathrm{E}$; Borg units $\cdot \mathrm{L}^{-1} \cdot \mathrm{min}^{-1}$ ).

\section{Statistical analysis}

Data are presented as mean and SD for normally distributed variables (Kolmogorov-Smirnov), and median (range) otherwise. Pearson's correlation coefficient was used to assess the level of association between continuous variables. Backward stepwise multiple linear regression was performed to define the independent predictors of peak $V^{\prime} \mathrm{O}_{2}$ (\% pred); resting variables that were significantly related to peak $V^{\prime} \mathrm{O}_{2}$ at the $10 \%$ level $(\mathrm{p}<0.10)$ were considered for inclusion in the model. In the regression analysis, however, only variables independently related to peak $V^{\prime} \mathrm{O}_{2}$ at the $5 \%$ level $(\mathrm{p}<0.05)$ were allowed to remain in the final model. One-way ANOVA with post-hoc Scheffe test was used to compare variables between the IC/ TLC groups. Receiver operating characteristic (ROC) curves were obtained for selected resting physiological variables, in order to predict a severely reduced maximal exercise capacity (peak $V^{\prime} \mathrm{O}_{2}<60 \%$ pred). The areas under the ROC curves were then compared according to DeLONG et al. [15] for pairwise differences. Sensitivity, specificity, positive and negative predictive values, positive and negative likelihood ratios, and accuracy were calculated for the cut-offs derived from the ROC curves. The level of statistical significance was set at $5 \%$ for all hypothesis tests $(\mathrm{p}<0.05)$.

\section{RESULTS}

\section{Population characteristics}

Resting and exercise characteristics are presented in table 1. On average, patients had moderate-to-severe airflow obstruction with evidence of air trapping $(n=44)$ and lung hyperinflation $(\mathrm{n}=18)$. Maximal exercise capacity (peak $V^{\prime} \mathrm{O}_{2}$ ) was below the lower limit of normal in 38 patients (86.3\%) [12] and 16 subjects $(36.3 \%)$ had a severe reduction in peak $V^{\prime} \mathrm{O}_{2}(<60 \%$ pred). Pulmonary-ventilatory limitation, as indicated by increased $V^{\prime}$ Emax/maximal voluntary ventilation ratio $(>0.8)$, was found in all subjects; accordingly, dyspnoea was the main exercise limiting symptom (table 1).

\section{Relationship between resting parameters and maximal exercise capacity}

Maximal exercise capacity (peak $V^{\prime} \mathrm{O}_{2}, \%$ pred) was significantly related to a number of resting variables, including: IC/ TLC ( $r=0.45$, fig. 1$)$, IC $(r=0.26)$, TLC $(r=0.38)$, RV $(r=0.48)$, and FEV1 $(r=0.58)$. After multiple regression analysis, which 


\begin{tabular}{|c|c|}
\hline $\begin{array}{l}\text { TABLE } 1 \\
\text { exerc }\end{array}$ & $\begin{array}{l}\text { Patient characteristics at rest and maximal } \\
\text { exercise }\end{array}$ \\
\hline Variables & \\
\hline Subjects $\mathbf{n}$ & 44 \\
\hline \multicolumn{2}{|c|}{ Demographic/anthropometric } \\
\hline Sex M/F & $33 / 11$ \\
\hline Age yrs & $64.1 \pm 7.5$ \\
\hline $\mathrm{BMI} \mathrm{kg} \cdot \mathrm{m}^{-2}$ & $23.7 \pm 4.0$ \\
\hline \multicolumn{2}{|l|}{ Pulmonary function } \\
\hline FEV 1 L & $1.24 \pm 0.49$ \\
\hline FEV $1 \%$ pred & $49.0 \pm 16.4$ \\
\hline FVC \% pred & $89.3 \pm 21.8$ \\
\hline $\mathrm{FEV}_{1} / \mathrm{FVC}$ & $0.43 \pm 0.09$ \\
\hline TLC \% pred & $116.8 \pm 16.4$ \\
\hline RV \% pred & $205.2 \pm 60.7$ \\
\hline RV/TLC & $0.55 \pm 0.09$ \\
\hline IC \% pred & $79.4 \pm 17.2$ \\
\hline IC/TLC & $0.31 \pm 0.07$ \\
\hline DL,CO \% pred & $55.8 \pm 18.9$ \\
\hline $\mathrm{Pa}, \mathrm{O}_{2} \mathrm{mmHg}$ & $66.5 \pm 8.6$ \\
\hline $\mathrm{Pa}, \mathrm{CO}_{2} \mathrm{mmHg}$ & $41.3 \pm 6.2$ \\
\hline \multicolumn{2}{|l|}{ Maximal exercise } \\
\hline Peak $V^{\prime} \mathrm{O}_{2} \%$ pred & $68.4 \pm 16.5$ \\
\hline Peak $V^{\prime} \mathrm{O}_{2} \mathrm{~mL} \cdot \mathrm{min}^{-1}$ & $998 \pm 342$ \\
\hline Power W & $64 \pm 29$ \\
\hline$V^{\prime} E L \cdot \min ^{-1}$ & $38.0 \pm 13.5$ \\
\hline$V^{\prime} E / M V V$ & $0.83 \pm 0.18$ \\
\hline RR breaths $\cdot \mathrm{min}^{-1}$ & $31.5 \pm 5.1$ \\
\hline$V T L$ & $1.20 \pm 0.37$ \\
\hline VT/resting IC & $0.57 \pm 0.15$ \\
\hline fc \% pred & $85.9 \pm 11.5)$ \\
\hline Dyspnoea score & $7(5-10)$ \\
\hline Dyspnoea/V'E & $0.18 \pm 0.10$ \\
\hline
\end{tabular}

Data are presented as mean \pm SD or median (range), unless otherwise stated. M: male; F: female; BMI: body mass index; FEV1: forced expiratory volume in one second; \% pred: \% predicted; FVC: forced vital capacity; TLC: total lung capacity; RV: residual volume; IC: inspiratory capacity; $D L, C O$ : diffusing capacity of the lung for carbon monoxide; $\mathrm{Pa}_{\mathrm{a}} \mathrm{O}_{2}$ : arterial oxygen tension; $\mathrm{Pa}_{1} \mathrm{CO}_{2}$ : carbon dioxide arterial tension; $V^{\prime} \mathrm{O}_{2}$ : oxygen uptake; $V^{\prime} \mathrm{E}$ : minute ventilation; MVV: maximal voluntary ventilation; RR: respiratory rate; $V T$ : tidal volume; $f C$ : cardiac frequency. $1 \mathrm{mmHg}=0.133 \mathrm{kPa}$.

considered all of these variables, only IC/TLC and FEV1 remained as independent predictors in the final model: peak $V^{\prime} \mathrm{O}_{2}(\%$ pred $)=78.9 \mathrm{IC} / \mathrm{TLC}+26.1 \mathrm{FEV} 1(\%$ pred $)+29.4(\mathrm{p}<0.01$; $\left.\mathrm{r}^{2}=0.334\right)$.

\section{Lung function predictors of a severely reduced maximal exercise capacity}

As IC/TLC was an independent predictor of peak $V^{\prime} \mathrm{O} 2$, this relationship was examined more carefully. As shown in figure 1, all but three patients with an IC/TLC $\leqslant 0.28$ (group I) had peak $V^{\prime} \mathrm{O}_{2}$ values $<60 \%$ pred. However, only three patients with an IC/TLC $>0.28$ (group II) had peak $V^{\prime} \mathrm{O}_{2}$ values $<60 \%$ pred. In fact, there were several between-group differences either at rest or during exercise (table 2). Group 1

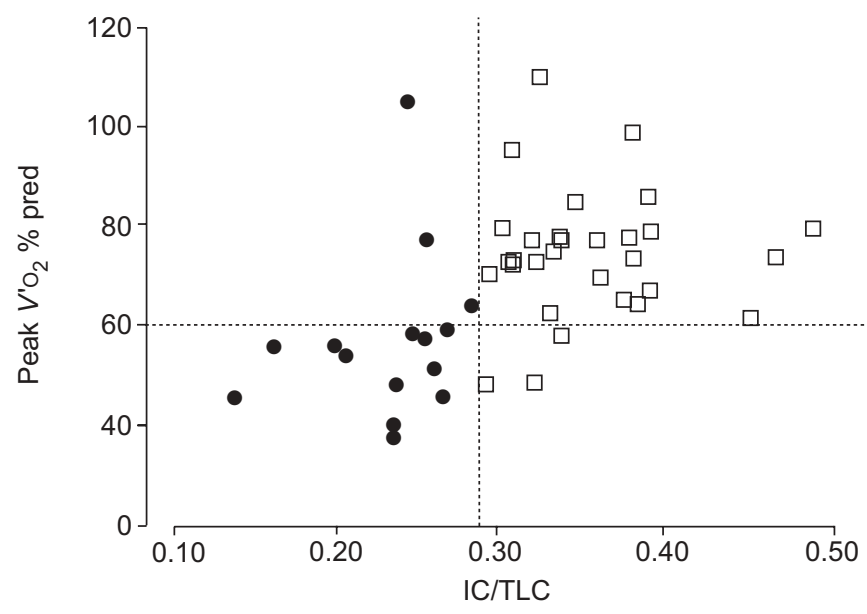

FIGURE 1. Relationship between inspiratory capacity (IC)/total lung capacity (TLC) ratio and maximal exercise capacity (peak oxygen uptake, $\mathrm{V}^{\prime} \mathrm{O}_{2}$ ) in a group of 44 patients with chronic obstructive pulmonary disease. \% pred: percentage of predicted. $\bullet$ : group $1 \mathrm{IC} / \mathrm{TLC}<0.28$; $\square$ : group $2 \mathrm{IC} / \mathrm{TLC}>0.28$.

patients had reduced BMI, worse lung function (airflow obstruction, air trapping and lung hyperinflation) and, as expected, lowest exercise capacity $(\mathrm{p}<0.05)$. Importantly, these patients tended to present with reduced $V \mathrm{~T}$ and increased ventilation-corrected dyspnoea scores (table 2).

In order to compare the resting physiological variables in their ability to predict a severely reduced peak $V^{\prime} \mathrm{O}_{2}$, the area under the ROC curves (AUC) for IC/TLC, IC (\% pred) and FEV1 ( $\%$ pred), were compared. As shown in figure 2, IC/TLC had the highest AUC (0.92); this value, however, showed a trend towards statistical difference $(p=0.06)$ from IC only. Based on this analysis, the cut-off points with the best sensitivity and specificity for each functional variable were selected [14]: IC/ $\mathrm{TLC}=0.28, \mathrm{IC}=75 \%$ pred, and $\mathrm{FEV} 1=50 \%$ pred. As shown in table 3 , an IC/TLC $\leqslant 0.28$ was associated with the highest specificity, positive predictive value, likelihood ratio for positive and negative test results, and overall accuracy to predict a peak $V^{\prime} \mathrm{O}_{2}<60 \%$ pred as compared with other variables.

\section{DISCUSSION}

The main original finding of the present study was that postbronchodilator IC/TLC ratio or inspiratory fraction, an index of increased lung volumes, was an independent predictor of maximal exercise capacity in patients with COPD. More specifically, an IC/TLC $\leqslant 0.28$ was likely to be related to a severely reduced peak $V^{\prime} \mathrm{O}_{2}(<60 \%$ pred); conversely, higher IC/TLC values were commonly found in less disabled patients. These data, in association with those previously reported by CASANOVA et al. [6], which related to mortality, indicate that the IC/TLC should be valued as a relevant index of prognosis $(\leqslant 0.25)$ and disability $(\leqslant 0.28)$ in patients with COPD.

\section{Lung hyperinflation and exercise tolerance in COPD}

It has long been recognised that the main pathophysiological abnormality during dynamic exercise in COPD is expiratory flow limitation; its consequences, however, are largely inspiratory and elastic as a result of $\mathrm{DH}$ [16]. Not surprisingly, several 


\begin{tabular}{|c|c|c|}
\hline \multirow[t]{2}{*}{ TABLE 2} & \multicolumn{2}{|c|}{$\begin{array}{l}\text { esting and exercise parameters of patients according to inspiratory fraction (inspiratory capacity (IC)/ total lung } \\
\text { apacity (TLC)) }\end{array}$} \\
\hline & Group $\mathrm{I}^{\#}$ & Group II" \\
\hline Subjects n & 15 & 29 \\
\hline \multicolumn{3}{|c|}{ Demographic/anthropometric } \\
\hline Age yrs & $65.2 \pm 6.8$ & $63.5 \pm 7.9$ \\
\hline \multicolumn{3}{|l|}{ Pulmonary function } \\
\hline FEV $1 \%$ pred & $38.4 \pm 14.7$ & $54.5 \pm 14.5^{\star}$ \\
\hline TLC \% pred & $125.4 \pm 18.7$ & $112.3 \pm 13.4^{*}$ \\
\hline RV \% pred & $255.4 \pm 64.3$ & $179.3 \pm 39.3^{*}$ \\
\hline RV/TLC & $0.64 \pm 0.07$ & $0.51 \pm 0.07^{\star}$ \\
\hline IC \% pred & $65.0 \pm 7.0$ & $86.8 \pm 16.2^{*}$ \\
\hline \multicolumn{3}{|l|}{ Maximal exercise } \\
\hline Peak $V^{\prime} \mathrm{O}_{2} \%$ pred & $56.8 \pm 16.6$ & $74.4 \pm 13.2^{*}$ \\
\hline Peak $V^{\prime} \mathrm{O}_{2} \mathrm{~mL} \cdot \mathrm{min}^{-1}$ & $784 \pm 319$ & $1109 \pm 302^{*}$ \\
\hline Power W & $48 \pm 29$ & $71 \pm 26^{*}$ \\
\hline$V^{\prime} E L \cdot \min ^{-1}$ & $29.9 \pm 11.6$ & $42.2 \pm 12.6^{*}$ \\
\hline$V^{\prime} E / M V V$ & $0.83 \pm 0.18$ & $0.83 \pm 0.18$ \\
\hline $\mathrm{RR}$ breaths $\cdot \mathrm{min}^{-1}$ & $28 \pm 3$ & $32 \pm 5^{\star}$ \\
\hline VT L & $1.04 \pm 0.35$ & $1.28 \pm 0.35^{\star}$ \\
\hline$V_{T} /$ resting IC & $0.61 \pm 0.20$ & $0.55 \pm 0.11$ \\
\hline fc \% pred & $87.0 \pm 9.5$ & $85.5 \pm 12.3$ \\
\hline Dyspnoea/V'E & $0.22 \pm 0.14$ & $0.17 \pm 0.07$ \\
\hline
\end{tabular}

Data are presented as mean \pm SD unless otherwise stated. BMI: body mass index; FEV1: forced expiratory volume in one second; \% pred: \% predicted; RV: residual volume; $\mathrm{DL}, \mathrm{CO}$ : diffusing capacity of the lung for carbon monoxide; $\mathrm{Pa}, \mathrm{O}_{2}$ : arterial oxygen tension; $\mathrm{Pa}_{2} \mathrm{CO}_{2}$ : carbon dioxide arterial tension; $\mathrm{V}^{\prime} \mathrm{O}_{2}$ : oxygen uptake; $\mathrm{V}^{\prime} \mathrm{E}$ : minute ventilation; MV: maximal voluntary ventilation; RR: respiratory rate; VT: tidal volume; $f$ C:cardiac frequency. ${ }^{*}: p<0.05$ group I versus group II. ${ }^{\#}:$ IC/TLC $\leqslant 0.28$; ${ }^{*}$ IC/TLC $>0.28 .1 \mathrm{mmHg}=0.133 \mathrm{kPa}$.

authors have found that a decrease in the operating volumes with bronchodilators, especially the end-expiratory lung volume (EELV), are more likely to be related to clinically meaningful changes in this patient population than traditional measures of airflow [17-20]. Similarly, improvement in exercise capacity and dyspnoea after lung-volume reduction surgery was better associated with changes in EELV than with FEV1 [21]. In the present study, measures of increased lung volumes (IC, RV and IC/TLC) were all associated with worsening maximum exercise capacity (table 2). Reduction in exercise tolerance in patients with lower IC/TLC values (group I) tended to be associated with lower $V \mathrm{~T}$ and increased ventilation-corrected dyspnoea at peak exercise (table 2). These results seem to indicate that with exercise progression, patients breathed at near-maximum (and less compliant) lung volumes, although exercise IC values were not measured in the present study (see Study limitations).

\section{Physiological significance of IC/TLC}

The theoretical advantage of IC/TLC over IC in isolation may be related to the fact that a lower IC/TLC seems to better reflect the deleterious combination of air trapping (increased RV and RV/TLC) plus lung hyperinflation (increased TLC; table 2). Therefore, two patients may present with similar IC which is a widely different fraction of their maximal available volume for lung expansion. In this context, the combination of lower IC/TLC with increased TLC (i.e. a very high EELV) is potentially more harmful than the isolated reduction in IC, since the patient should breathe at his/her near-maximum (and increased) TLC, with negative consequences on the elastic work of breathing and dyspnoea.

A noticeable finding of the present study was the close similarity between the IC/TLC cut-off for severe reduction in peak $V^{\prime} \mathrm{O}_{2}$ described herein, and that found by CASANOVA et al. [6] for mortality in COPD. Although the exact nature of the relationship between lung hyperinflation and mortality in COPD is still elusive, it is interesting to note that a low IC/TLC was related to reduced BMI, worse exercise capacity and, marginally $(\mathrm{p}=0.10)$, to decreased $D \mathrm{~L}, \mathrm{CO}$ (table 2$)$, all indicators of poor prognosis in COPD [22].

\section{Clinical implications}

Exercise capacity has been associated with disability, increased usage of healthcare resources and even mortality in patients with COPD [23]. Resting lung function measurements may be useful in estimating the likelihood of a severe reduction in 


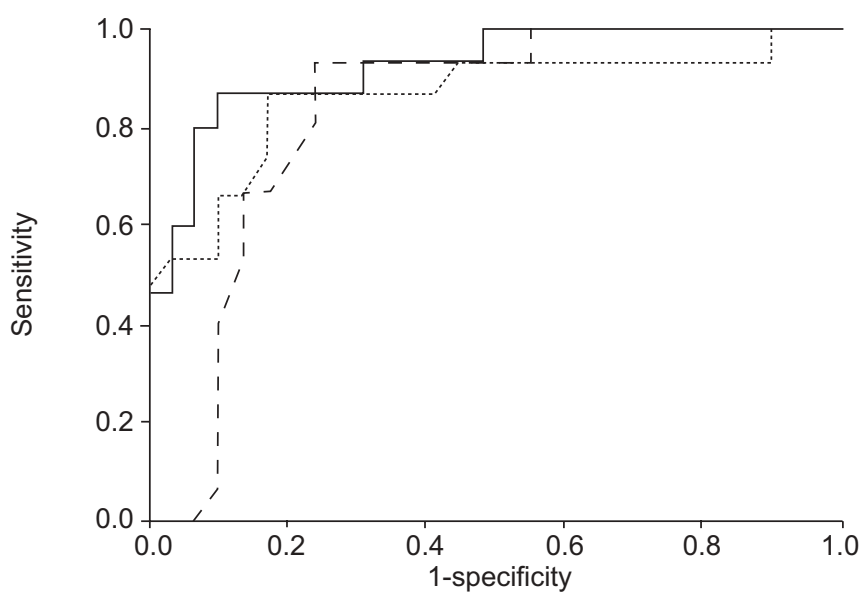

FIGURE 2. Receiver operating characteristic curves of inspiratory capacity (IC)/total lung capacity (TLC; - ), IC \% predicted (- - ) and forced expiratory volume in one second $(\mathrm{FEV} 1) \%$ pred $(\cdots)$, as related to a severely reduced maximal exercise capacity (peak oxygen uptake, $V^{\prime} \mathrm{O}_{2},<60 \%$ pred). The best cut-off values were $0.28,75 \%$ pred and $50 \%$ pred, respectively. The area under the curve (AUC; 95\% confidence interval) was $0.92(0.84-1.00), 0.83(0.70-0.95)$ and 0.86 (0.73-0.99) for IC/TLC, IC \% pred and FEV1, respectively. Differences between AUCs were IC/TLC versus FEV $1, p=0.30$; IC/TLC versus $I C, p=0.06$; and FEV 1 versus $\mathrm{IC}, \mathrm{p}=0.66$

exercise tolerance [5]. The present results show that IC/TLC is a readily available alternative for the prediction of severe disability in COPD, with the advantage of also being associated with mortality [6]. From a practical point of view, if a COPD patient presents with an IC/TLC $\leqslant 0.28$ (or $\leqslant 0.25$ ), he/she should be considered at increased risk of respiratoryrelated disability and death.

\section{Study limitations}

A major limitation of the present study is related to the sample size. Therefore, it cannot be ruled out that failure to demonstrate a potential superiority of IC/TLC over other physiological variables was due to an insufficient number of patients with severe-to-very severe lung hyperinflation. In fact, the present results should not be extrapolated for patients with more advanced or milder disease. Another relevant limitation was the lack of IC measurements during exercise, a physiological outcome that has been shown to be superior to resting IC in estimating exercise tolerance in patients with COPD [1]. It could be speculated, however, that as patients with lower IC/ TLC had substantially increased operating lung volumes at rest, as discussed above, they would tend to present with lower exercise IC. However, recent studies using optoelectronic plethysmography have found a variable behaviour of exercise lung volumes in individual COPD patients, DH being poorly related to static lung volumes [24, 25]. Future studies are therefore warranted to evaluate how IC/TLC compares to exercise IC in these patients. Also of importance is that, submaximal exercise tolerance has been found to be more closely related to patients functional capacity than peak exercise; the accuracy of IC/TLC in identifying patients with reduced tolerance to endurance exercise remains to be investigated [26]. Moreover, it is currently unknown whether pre-bronchodilator IC/TLC has any functional significance.

\begin{tabular}{|c|c|c|c|}
\hline \multirow[t]{2}{*}{ TABLE 3} & \multicolumn{3}{|c|}{$\begin{array}{l}\text { Diagnosis performance of different lung function } \\
\text { parameters in predicting a severely reduced } \\
\text { maximal exercise capacity }{ }^{\#}\end{array}$} \\
\hline & IC/TLC $\leqslant 0.28$ & IC $\leqslant 75 \%$ pred & FEV $_{1} \leqslant \mathbf{5 0} \%$ pred \\
\hline Sensitivity \% & 80.0 & 93.3 & 86.6 \\
\hline Specificity \% & 89.6 & 75.8 & 58.2 \\
\hline PPV \% & 80.0 & 66.6 & 52.0 \\
\hline NPV \% & 89.6 & 95.6 & 89.4 \\
\hline Accuracy \% & 86.3 & 81.8 & 68.1 \\
\hline LR positive test & 7.2 & 3.7 & 2.0 \\
\hline LR negative test & 0.20 & 0.93 & 0.24 \\
\hline \multicolumn{4}{|c|}{$\begin{array}{l}\text { IC: inspiratory capacity; TLC: total lung capacity; FEV1: forced expiratory } \\
\text { volume in one second; \% pred: \% predicted. PPV: positive predictive value; } \\
\text { NPV: negative predictive value; LR: likelihood ratio. }{ }^{\#} \text { : peak oxygen uptake } \\
<60 \% \text { pred. }\end{array}$} \\
\hline
\end{tabular}

Finally, as mentioned, exercise intolerance is a multi-factorial construct where pulmonary-ventilatory, cardiovascular and peripheral factors interact in a complex way; IC/TLC (as any lung function variable) should always be used in association with other indices to estimate the degree of effort intolerance in the individual patient.

In summary, the present study has shown, for the first time, that the post-bronchodilator inspiratory fraction (inspiratory capacity/total lung capacity) is an independent predictor of severely reduced maximal exercise capacity in patients with chronic obstructive pulmonary disease. Considering that this variable has also been previously found to constitute a significant prognostic index in chronic obstructive pulmonary disease [6], the inspiratory fraction should be valued in the functional evaluation of this patient population.

\section{ACKNOWLEDGEMENTS}

The authors would like to thank L. de Moura for language revision, L. Maris Nápolis for assistance with data analysis, the Methods in Epidemiologic, Clinical and Operations Research (MECOR) course (provided by the American Thoracic Society), and C. Gross (University of Washington, Washington, WA, USA), for useful insights on data analysis and interpretation.

\section{REFERENCES}

1 O’Donnell DE, Revil SM, Webb KA. Dynamic hyperinflation and exercise intolerance in chronic obstructive pulmonary disease. Am J Respir Crit Care Med 2001; 164: 770-777.

2 Calverley PM, Koulouris NG. Flow limitation and dynamic hyperinflation: key concepts in modern respiratory physiology. Eur Respir J 2005; 25: 188-199.

3 O'Donnell DE, Bertley JC, Chau LK, Webb KA. Qualitative aspects of exertional breathlessness in chronic airflow limitation. Am J Respir Crit Care Med 1997; 155: 109-115.

4 Carlson DJ, Ries AL, Kaplan RM. Predicting maximal exercise tolerance in patients with COPD. Chest 1991; 100: 307-311. 
5 Diaz O, Villafranca C, Ghezzo H, et al. Role of inspiratory capacity on exercise tolerance in COPD patients with and without tidal expiratory flow limitation at rest. Eur Respir J 2000; 16: 269-275.

6 Casanova C, Cote C, Torres JP, et al. Inspiratory-to-total lung capacity ratio predicts mortality in patients with chronic obstructive pulmmonary disease. Am J Respir Crit Care Med 2005; 171: 591-597.

7 Nishimura K, Izumi T, Tsukino M, Oga T. Dyspnea is a better predictor of 5-year survival than airway obstruction in patients with COPD. Chest 2002; 121: 1434-1440.

8 National Heart, Lung and Blood Institute and World Health Organization. Global initiative for chronic obstructive lung disease: global strategy for diagnosis, management, and prevention of chronic obstructive pulmonary disease. 2005 update. www.goldcopd.com. Date last accessed: September 2006.

9 Pereira CAC, Barreto SP, Simões JG, Pereira FWL, Gerstler JG, Nakatani J. Spirometric reference values for a sample of Brazilian adult population. Braz J Pneumol 1992; 18: 10-22.

10 American Thoracic Society/European Respiratory Society Task Force. Standardisation of the single-breath determination of carbon monoxide uptake in the lung. Eur Respir J 2005; 26: 720-735.

11 Neder JA, Andreoni S, Castelo-Filho A, Nery LE. Reference values for lung function tests. I Static volumes. Braz J Med Biol Res 1999; 32: 703-717.

12 Ruppel GL. Lung volumes and gas distribution tests. In: Ruppel GL, ed. Manual of Pulmonary Function Testing. St. Louis, Mosby, 1998; pp. 69-94.

13 Neder JA, Nery LE, Castelo A, et al. Prediction of metabolic and cardiopulmonary responses to maximum cycle ergometry: a randomized study. Eur Respir J 1999; 14: 1304-1313.

14 Borg GAV. Psychophysical basis of perceived exertion. Med Sci Sports Exercise 1982; 14: 377-381.

15 Delong ER, Delong DM, Clarke-Pearson DL. Comparing the areas under two or more correlated receiver operating characteristic curves: a nonparametric approach. Biometrics 1988; 44: 837-845.
16 Aliverti A, Macklem P. How and why exercise is impaired in COPD. Respiration 2001; 68: 229-239.

17 O'Donnell DE, Lam M, Webb KA. Spirometric correlates of improvement in exercise performance after anticholinergic therapy in chronic obstructive pulmonary disease. Am J Respir Crit Care Med 1999; 160: 542-549.

18 Celli B, Wallack RZ, Wang S, Kesten S. Improvement in resting inspiratory capacity and hyperinflation with tiotropium in COPD patients with increased static lung volumes. Chest 2003; 124: 1743-1748.

19 Belman MJ, Botnick WC, Shin JW. Inhaled bronchodilators reduce dynamic hyperinflation during exercise in patients with chronic obstructive pulmonary disease. Am J Respir Crit Care Med 1996; 153: 967-975.

20 O'Donnell DE. Assessment of bronchodilator efficacy in symptomatic. Is spirometry useful? Chest 2003; 117: 42S.

21 Martinez F, De Oca MM, Whyte RI, Stetz J, Gay SE, Celli B. Lung volume reduction improve dyspnea, dynamic hyperinflation, and respiratory muscle function. Am J Respir Crit Care Med 1997; 155: 1984-1990.

22 Celli B, Cote C, Marin JM, et al. The body mass index, airflow obstruction, dyspnea, exercise performance (BODE) index in chronic obstructive pulmonary disease. N Engl J Med 2004; 350: 1005-1012.

23 Oga T, Nishimura K, Tsukino M, Sato S, Hajiro T. Analysis of the factors related to mortality in chronic obstructive pulmonary disease: role of exercise capacity and health status. Am J Respir Crit Care Med 2003; 167: 544-549.

24 Oga T, Nishimura K, Tsukino M, Hajiro T, Ikeda A, Izumi T. The effects of oxitropium bromide on exercise performance in patients with stable chronic obstructive pulmonary disease. A comparison of three different exercise tests. Am J Respir Crit Care Med 2000; 161: 1897-1901.

25 Aliverti A, Stevenson N, Dellacà RL, Lo Mauro A, Pedotti A, Calverley PM. Regional chest wall volumes during exercise in chronic obstructive pulmonary disease. Thorax 2004; 59: 210-216.

26 Vogiatzis I, Georgiadou O, Golemati S, et al. Patterns of dynamic hyperinflation during exercise and recovery in patients with severe chronic obstructive pulmonary disease. Thorax 2005; 60: 723-729. 